\title{
Ten years' leprosy control work in Malaŵi (Central Africa)-II Patterns of endemicity since 1973
}

\author{
J M PONNIGHAUS* \& G BOERRIGTER $\dagger$ \\ *LEPRA Evaluation Project, PO Box 46, Chilumba, Malawi i; \\ $\dagger$ †EPRA Control Project, PO Box 148, Lilongwe, Malâ̂i
}

Accepted for publication 12 March 1986

Summary The British Leprosy Relief Association (LEPRA) has been operating a vertically structured mobile leprosy control service in 5 districts in the Southern Region of Malawi (Central Africa) since 1966. This service was extended from 1973 onwards to the whole country with the exception of the two most southern districts.

Data concerning the patterns of endemicity of leprosy from 1974 to 1983 have been extracted from the available records of the LEPRA Control Project. It would seem that there are at least two distinctly different endemic situations in Malawi: districts on the Central African Plateau are characterized by a low level of endemicity of leprosy, while the districts in the Rift Valley along the shore of Lake Malawi have a level of endemicity that is five times higher. In both areas a parallel decline in detection rates has been observed since 1978-79.

The authors consider this decline in detection rates to be a reflection of a genuine decline in incidence rates. This decline is accompanied by a trend towards higher lepromatous rates and shifts in the relative age distribution of new leprosy patients towards older age groups.

Projections are given concerning the expected numbers of new leprosy patients to be detected annually from 1984 to 1988 .

\section{Introduction}

The British Leprosy Relief Association (LEPRA) started operating a leprosy control service (LCP) in 5 districts in the Southern Region of Malawi (Central Africa) in 1966. From 1973 onwards LEPRA extended its mobile services to the rest of the country with the exclusion of the Lower Shire Valley in the far south. It is the intention of this paper to analyse data collected in conjunction with this programme in order to study the patterns and recent trends of leprosy in Malawii.

It is notoriously difficult to analyse and interpret correctly data routinely collected in leprosy control projects. ${ }^{1}$ A major problem arises from the fact that 
such data tend to reflect the activity of the control services rather than the activity of the disease in the community. Any absence of information tends to be ambiguous as it might mean that something was not recorded because it was in fact absent, or it might mean that something was present but not recorded, or it might mean it was not even looked for. Even the presence of information tends to be problematic in so far as there is rarely any indication of the quality of the information recorded.

Finally the terms used on routine records are often undefined or unstandardized and thus their meaning may have shifted over time.

When looking at the available data from the LCP in Malawi we hope to overcome some of these difficulties by comparing different areas, assuming that the LCP was equally active in all the areas covered. Although we can present no evidence to support this assumption we feel it is a reasonable one given the vertical structure of the LCP as described in Part $\mathrm{I}^{2}$.

We are aware that there have been shifts in the use of certain terms during the 10 years' work on which this paper is based. But it would seem reasonable to presume that these shifts occurred more or less simultaneously in all areas covered by the LCP.

\section{Methods}

\section{(a) Numerators}

Data on previously untreated, newly registered leprosy patients were extracted from each District in Malawi. These were taken from individual patients' records. Data are included from thefirst full year that the LCP was present in that District.

\section{(b) Denominators}

The denominators used are based on the 1977 population census. ${ }^{3}$ Corrected estimates for other years were provided by the National Statistical Office. We chose mid-year population figures for our calculations. The age/sex distribution of the total population of Malawi for 1977 is shown in Figure 1. The total population in 1977 was $5,547,460 .^{3}$

\section{(c) Areas}

The districts were divided into three groups for analysis purposes. Group A consists of highland districts, $900-1400 \mathrm{~m}$ above sea level. These include Chitipa (since 1975), Rumphi (since 1976), Mzimba (sincé 1977), Kasungu (since 1975), Ntchisi (since 1978), Dowa (since 1975), Mchinji (since 1975) and Mwanza (since 1978). Group B consists of lowland districts, 472-900 m above sea level. These 


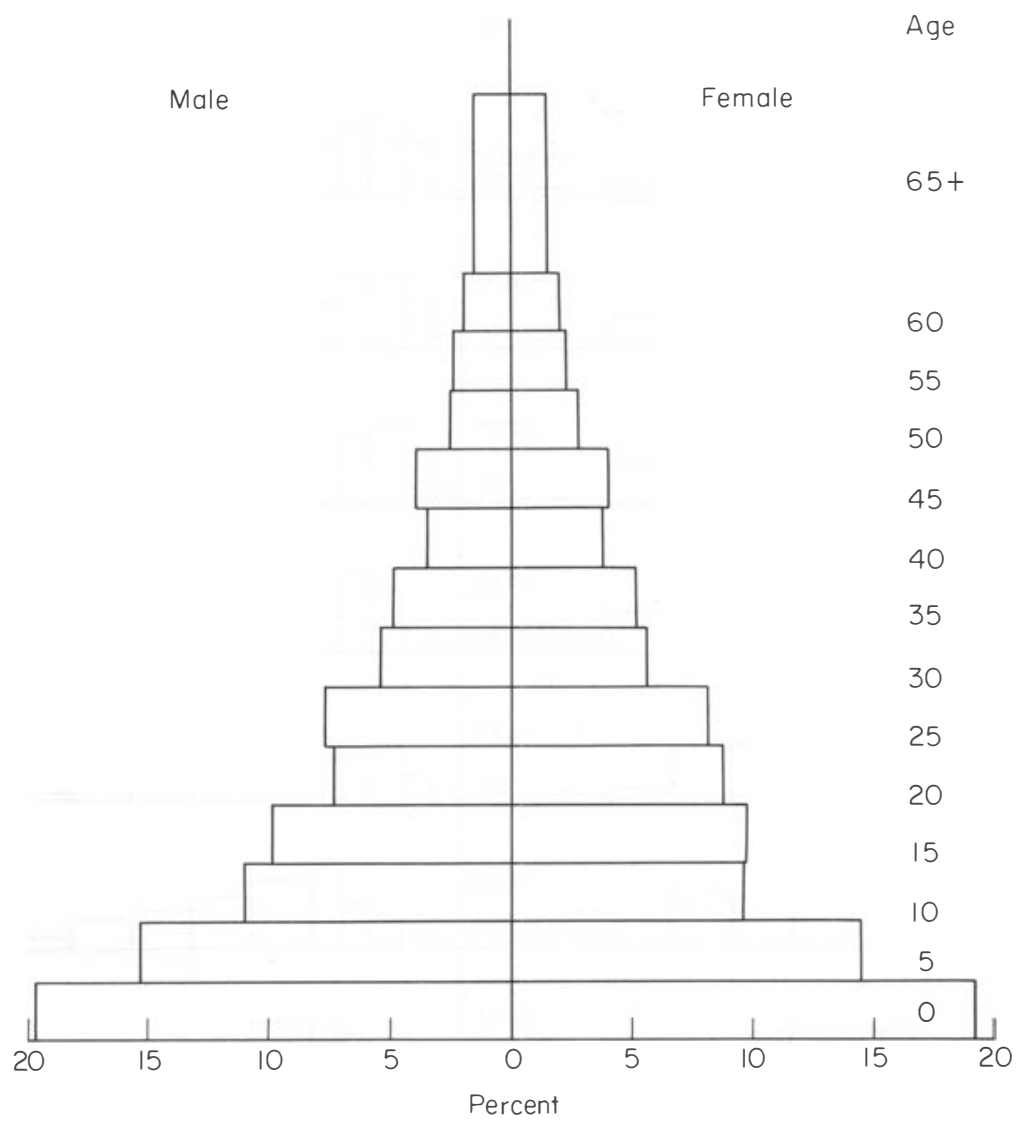

Figure 1. The age-sex distribution of the population of Malawii, 1977.

include Nkhata Bay (since 1976), Nkhotakota (since 1977), Salima (since 1975), Mangochi (since 1975), Machinga (since 1975) and part of the Zomba District (since 1975). This grouping into A and B groups first suggested itself to us on the basis of clear differences in the 1983 detection rates, which in the highland districts ranged from $0 \cdot 04$ to $0 \cdot 12$ (Mwanza 0.19) per thousand, compared with the lowland districts where the 1983 detection rates ranged from 0.35 to 0.49 (Machinga 0.28) per thousand.

Data for the Karonga District (since 1974) are shown separately, because of the total population survey conducted by the LEPRA Evaluation Project (LEP) since 1980. ${ }^{4}$ Lilongwe District, although on the highlands, was left out because of dramatic changes in the population structure related to the establishment of the capital city in that district. Dedza and Ntcheu Districts were left out because, although mostly on the plateau, they do include areas on the lowland towards the lake (see Paper I, Figure 1). 


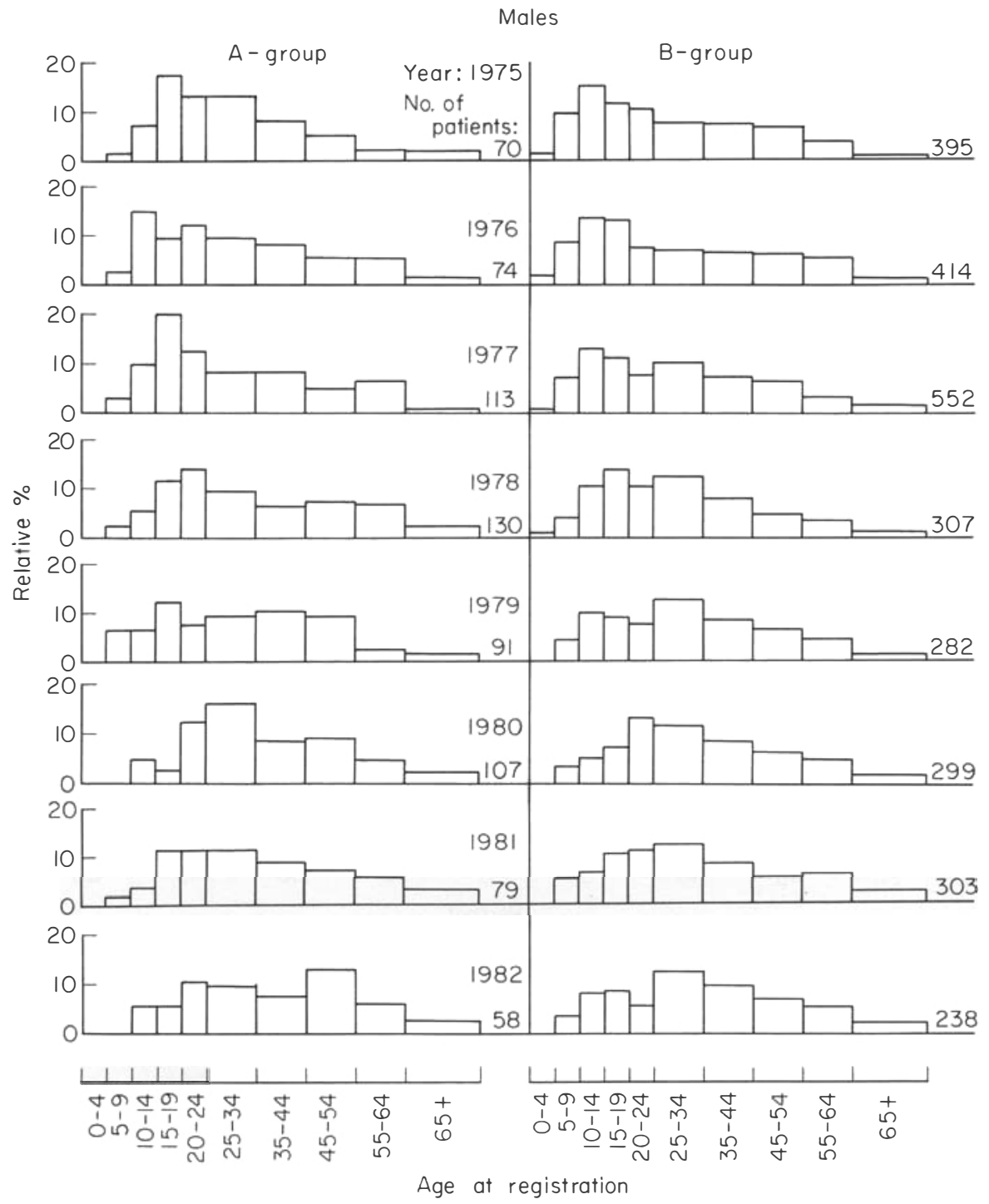

Figure 2. Number and relative age distribution of newly registered male leprosy patients, 1975-82, in highland (group A) and lowland (group B) districts in Malawii.

\section{(d) Years of birth and onset of disease}

Although years of birth often had to be guessed by the LCAs and the patients, we believe it is reasonable to present data in 5-year age-groups for patients under 25 years and in 10-year age-groups for patients of 25 years or more. Since we observed that LCAs frequently used the activity and the extent of clinical disease to decide on the time of onset, we do not wish to use the data on the onset of disease for any analysis. 
Females

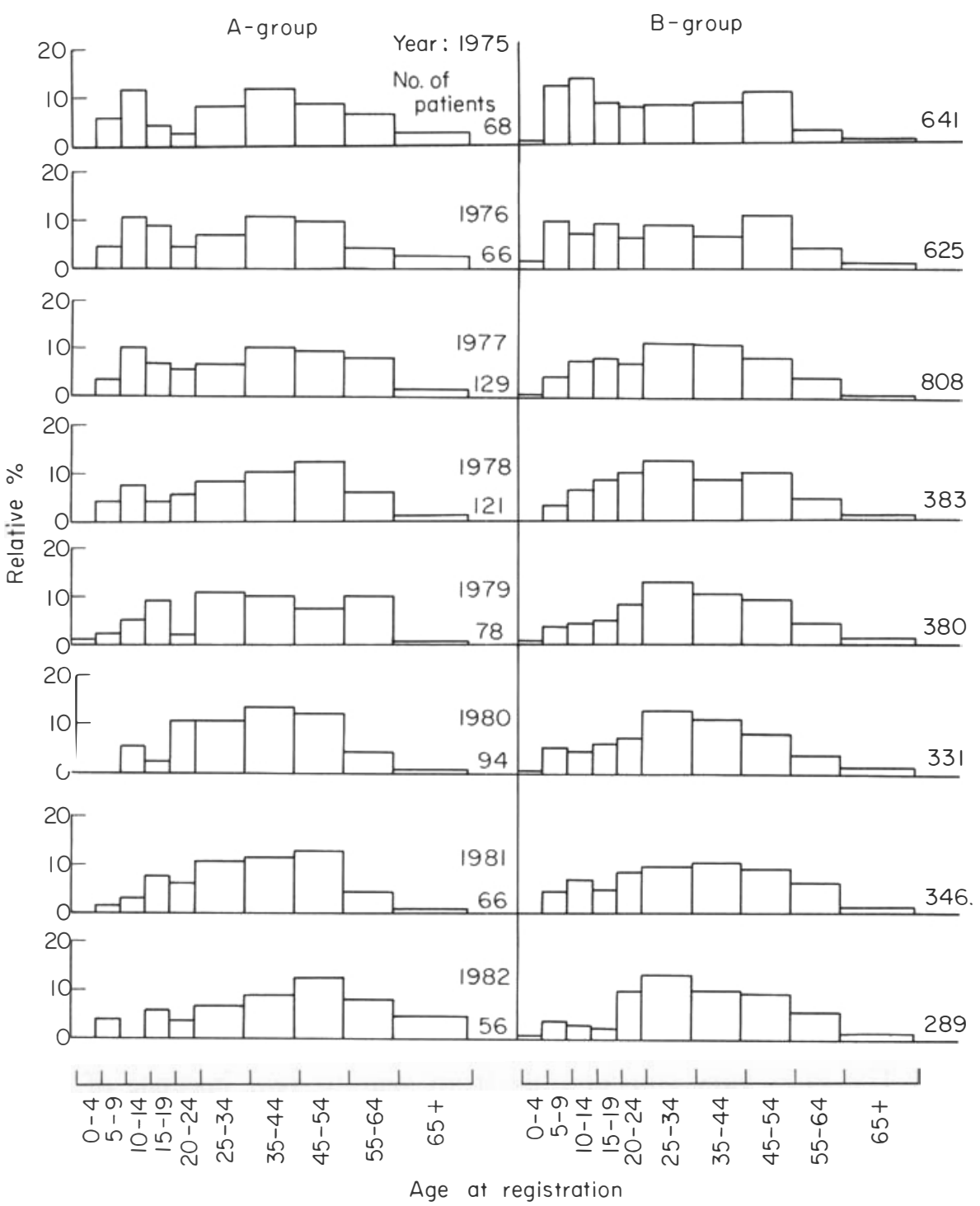

Figure 3. Number and relative age distribution of newly registered female leprosy patients, 1975-82, in highland (group A) and lowland (group B) districts in Malawi.

\section{(e) Ascertainment of cases}

Case detection methods, diagnostic facilities, and the quality of diagnosis and classification have been described in Part I. ${ }^{2}$ Therefore it may suffice to say that case detection was largely dependent on leprosy patients self-reporting to Clinical Attendants and Leprosy Control Assistants (LCAs). In addition there was 
limited active case detection in the context of school surveys and contact examinations. Cases were classified routinely by the LCAs as TT/BT, midborderline (BB) or BL/LL. ${ }^{2}$ There was, at least initially, a tendency to over-diagnose rather than to under-diagnose clinical leprosy. The help of histopathology for diagnosis and/or classification was not sought, but extensive use was made of the closely supervised slit-skin-smear service.

\section{Results}

\section{(a) Age/sex distribution}

Several differences become apparent when we compare the age distributions of newly registered leprosy patients in high altitude areas with those in low altitude areas (Figures 2-4). In all areas and for both sexes there is a shift towards older age groups in successive years since 1975. The proportion of young cases was particularly high in Karonga District for both males and females prior to 1978, and for males in both highland and lowland areas prior to 1979. Most of the distributions appear unimodal, with the possible exception of those for females in the highland areas prior to 1978 and for both males and females in Karonga District since 1980.

We do not think that the tendency towards older age groups is owing to changes in the methods of establishing ages.

\section{(b) Lepromatous rates}

Table 1 shows lepromatous rates for new male and female patients for groups A, $\mathrm{B}$ and Karonga District. A lepromatous patient is defined for this purpose as anyone registered as a new $\mathrm{BB}$ case with positive slit-skin smears or as a new BL/ LL case with a positive slit-skin-smear result within 6 months of registration or else with no slit-skin-smear result but clinical findings typical for lepromatous leprosy. The rates vary considerably from year to year because of the small numbers of lepromatous patients detected per year. This makes it difficult to reach firm conclusions on trends over the years. However it is evident that the lepromatous rates are consistently higher for males than for females. In addition, the lepromatous rates appear to have risen since 1975 for both sexes in both the highland and lowland areas. On the other hand, these rates have remained relatively constant in Karonga District.

\section{(c) Male-female ratios}

A consistent difference between highland (group A) and lowland districts (group B) in the proportion of males among new leprosy patients is shown in Table 2 . There has been a preponderance of male patients in the highland districts and a 
Kuronga district
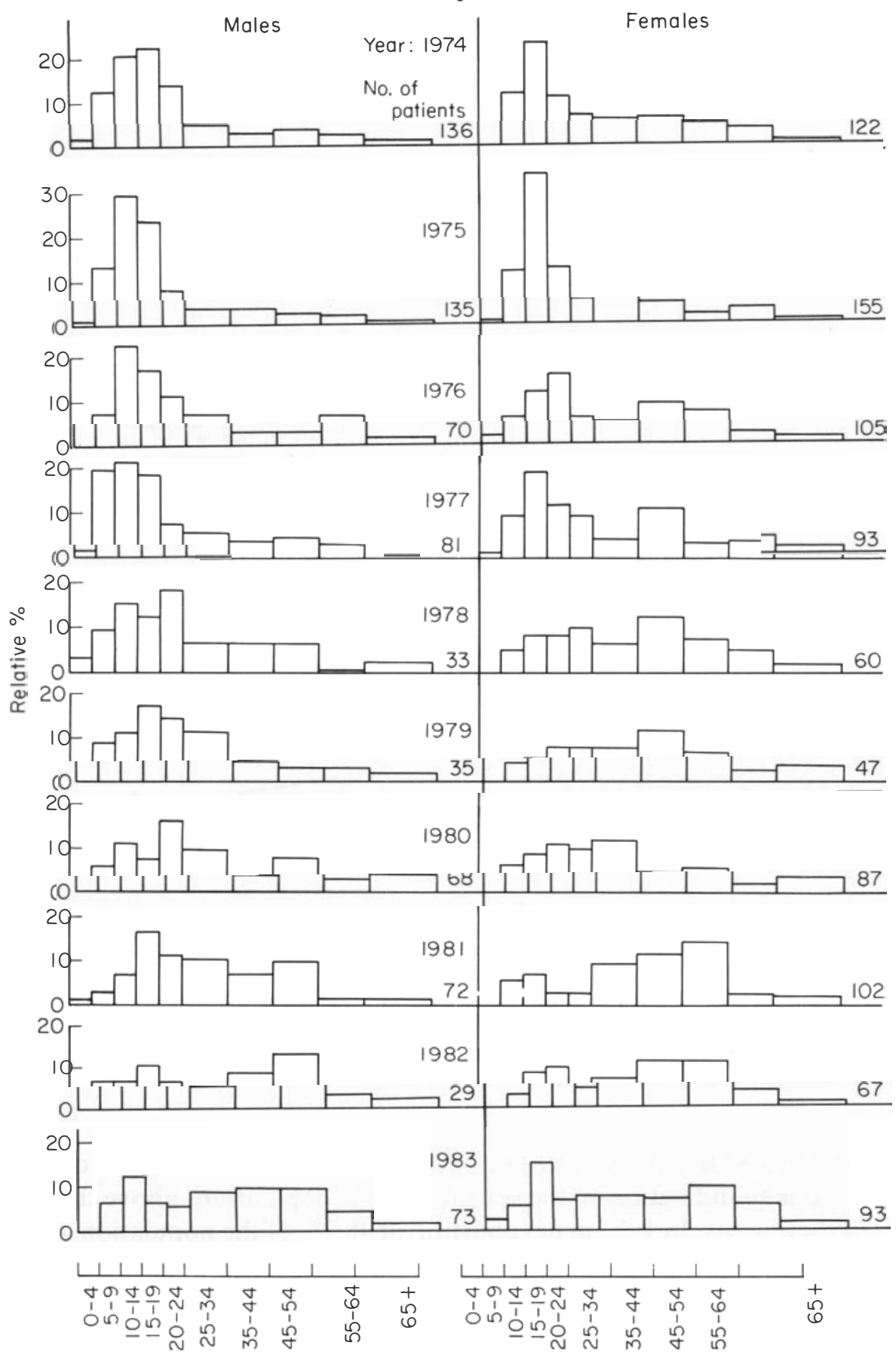

Age at registration

Figure 4. Number and relative age distribution of newly registered male and female leprosy patients, 1974-83 in Karonga District in Malawi. 


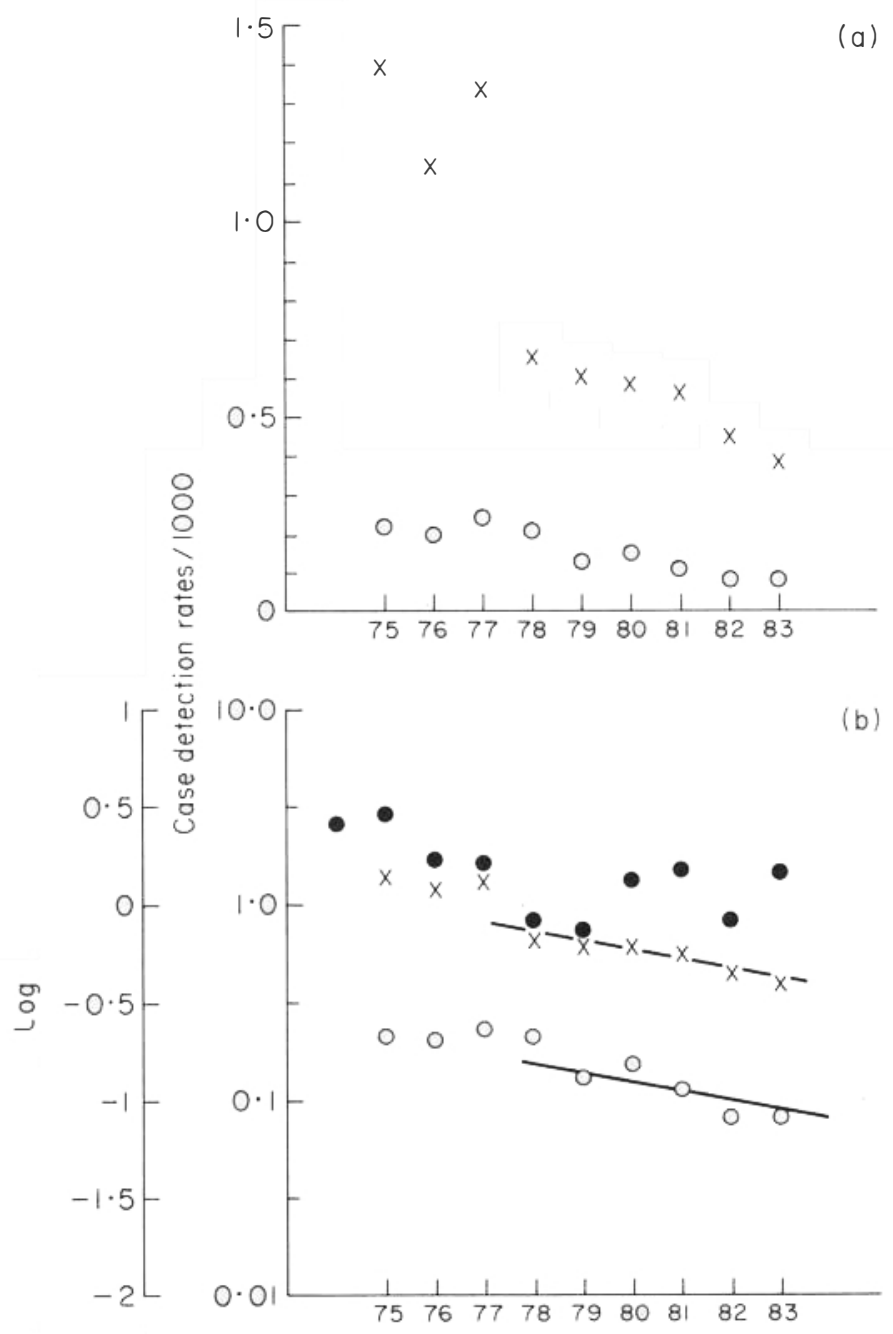

Figure 5. (a) Leprosy detection rates in lowland and highland districts in Malawi per 1000 population. Arithmetic scale. (b) Leprosy detection rates in Karonga District, lowland and highland districts in Malawi per 1000 population. Logarithmic scale. $\bigcirc$, highland districts (group A); $\times$, lowland districts (group B); $\bullet$, Karonga District.

preponderance of female patients in the lowland districts. This difference can only partly be due to differences in the sex ratio of the populations above the age of 9 years in these areas. In 1977 males constituted $48.7 \%$ of the population above the age of 9 years in the highland districts but only $45.3 \%$ of the population above the age of 9 years in the B-group districts. ${ }^{3}$ In Karonga District males constituted (in 1977) $46 \cdot 1 \%$ of the population above the age of 9 years. The proportion of males among leprosy patients in Karonga District, exceeded 50\% only in 1974 (which was the first year that the district was completely covered by the LEPRA mobile 
Table 1. Lepromatous rates among new patients detected by year and area. (Percentages)

\begin{tabular}{|c|c|c|c|c|c|c|}
\hline & \multicolumn{2}{|c|}{$\begin{array}{c}\text { Karonga } \\
\text { District }\end{array}$} & \multicolumn{2}{|c|}{$\begin{array}{l}\text { Highland } \\
\text { districts } \\
\text { (group A) }\end{array}$} & \multicolumn{2}{|c|}{$\begin{array}{l}\text { Lowland } \\
\text { districts } \\
\text { (group B) }\end{array}$} \\
\hline & Males & Females & Males & Females & Males & Females \\
\hline 1974 & $11 \cdot 0$ & $4 \cdot 1$ & & & & \\
\hline 1975 & 8.8 & $5 \cdot 2$ & $25 \cdot 7$ & $2 \cdot 9$ & $11 \cdot 6$ & $4 \cdot 5$ \\
\hline 1976 & $10 \cdot 0$ & $4 \cdot 7$ & $14 \cdot 8$ & $15 \cdot 2$ & $18 \cdot 4$ & $6 \cdot 7$ \\
\hline 1977 & $3 \cdot 7$ & $1 \cdot 1$ & $10 \cdot 6$ & $7 \cdot 0$ & $14 \cdot 7$ & $6 \cdot 8$ \\
\hline 1978 & $12 \cdot 1$ & $9 \cdot 1$ & $22 \cdot 3$ & $13 \cdot 3$ & $19 \cdot 2$ & $8 \cdot 3$ \\
\hline 1979 & $11 \cdot 4$ & $4 \cdot 2$ & $20 \cdot 8$ & $11 \cdot 5$ & $20 \cdot 9$ & $7 \cdot 6$ \\
\hline 1980 & $5 \cdot 8$ & $1 \cdot 1$ & $29 \cdot 9$ & $8 \cdot 5$ & $21 \cdot 7$ & $8 \cdot 8$ \\
\hline 1981 & $13 \cdot 8$ & $1 \cdot 0$ & $21 \cdot 5$ & $16 \cdot 6$ & $24 \cdot 4$ & $4 \cdot 9$ \\
\hline 1982 & $10 \cdot 3$ & $1 \cdot 5$ & $32 \cdot 7$ & $25 \cdot 0$ & $26 \cdot 4$ & $10 \cdot 3$ \\
\hline 1983 & $5 \cdot 5$ & $3 \cdot 2$ & & & & \\
\hline
\end{tabular}

Table 2. Male-female ratio among new patients detected by year and area.

\begin{tabular}{cccc}
\hline & & $\begin{array}{c}\text { Highland } \\
\text { Karonga } \\
\text { districts } \\
\text { District }\end{array}$ & $\begin{array}{c}\text { Lowland } \\
\text { districts } \\
\text { (group B) }\end{array}$ \\
\hline 1974 & $52 \cdot 7$ & & \\
1975 & $46 \cdot 6$ & $50 \cdot 7$ & $38 \cdot 1$ \\
1976 & $40 \cdot 0$ & $52 \cdot 9$ & $39 \cdot 8$ \\
1977 & $46 \cdot 6$ & $46 \cdot 7$ & $40 \cdot 6$ \\
1978 & $37 \cdot 5$ & $51 \cdot 8$ & $44 \cdot 5$ \\
1979 & $42 \cdot 7$ & $53 \cdot 8$ & $42 \cdot 6$ \\
1980 & $43 \cdot 9$ & $53 \cdot 2$ & $47 \cdot 5$ \\
1981 & $41 \cdot 4$ & $54 \cdot 5$ & $46 \cdot 7$ \\
1982 & $30 \cdot 2$ & $50 \cdot 9$ & $45 \cdot 2$ \\
1983 & $44 \cdot 0$ & & \\
\hline
\end{tabular}

service). Since then the majority of cases have been females as in all other lowland districts. Table 2 and Figure 4 also show that the proportion of males in Karonga District among newly registered cases dropped slightly with the institution of widespread active case detection by the LEPRA Evaluation Project (LEP). This suggests that, at least in Karonga District, new male patients were marginally more likely to self-report than new female patients. 
The slightly higher lepromatous rates in the highland districts are not likely to account for the differences in the proportion of males among new leprosy patients as observed between the lowland and the highland districts.

\section{(d) Detection rates}

Since the leprosy control projects have included some active case-finding (school surveys and contact surveys), detection rates are slightly higher than pure selfreporting rates but lower than true incidence rates. Data from the LEP indicate that the case detection rates are about two thirds of the true incidence rates at least in Karonga District. ${ }^{4}$

Not all districts were completely covered upon introduction of a mobile service to that district. Nonetheless we have consistently used total district populations as denominators. Thus in some districts the detection rate might be artificially low for the 'first year'. The first year in this context means the first year when mobile services were operational by the first of January in that district.

From the rates shown in Table 3 and in Figure 5 we can conclude: (i) That most of the backlog of new leprosy patients, without a history of having received antileprosy treatment before, had self-reported (or been detected) by the end of 1978 in Group A (highland) districts and by the end of 1977 in Group B districts along the lakeshore because of the sharp drop in detection rates in 1979 and 1978 respectively. One can probably also conclude from the Karonga District figures, that a small part of the backlog of patients remained unregistered, because the beginning of the main survey by the LEP in 1980 was characterized by a sharp increase in the detection rate; and (ii) that in the lowland districts (Group B) the endemic situation would appear to be different from the endemic situation in the highland districts (group A) because, although the decline in detection rates is similar to the one in Group A districts, the detection rates are still 5 times higher along the shore of Lake Malawi than on the western plateau.

\section{(e) Projections}

Annual case detection rates per 1000 population are shown separately for highland and lowland areas in Figure 5. Figure 5(a) shows the rates on an arithmetic scale, revealing a dramatic fall in both regions over the past 10 years. Figure 5(b) shows the rates on a logarithmic scale which reveals that the proportional fall has been very similar in the two areas. The similarity of these trends and their linearity on the logarithmic scale encourages us to predict future detection rates by extrapolating these (loglinear) trends. For group A districts expected detection rates for 1984-1988 were calculated by linear regression of the logarithms of the detection rates for 1979-1983, and for group B districts by linear regression of the logarithms of the detection rates for 1978-1983. Results of these projections are shown in Table 4(a). Multiplication of detection rates with 
Table 3. Detection rates per calendar year per thousand.

\begin{tabular}{lllllllllll}
\hline & 1974 & 1975 & 1976 & 1977 & 1978 & 1979 & 1980 & 1981 & 1982 & 1983 \\
\hline Group A & 0.22 & 0.20 & 0.24 & 0.21 & 0.13 & 0.15 & 0.11 & 0.08 & 0.08 \\
Group B* & 1.39 & 1.14 & 1.33 & 0.65 & 0.60 & 0.58 & 0.56 & 0.44 & 0.38 \\
Karonga & 2.61 & 2.87 & 1.69 & 1.64 & 0.81 & 0.73 & 1.35 & 1.49 & 0.80 & 1.46 \\
District & & & & & & & & & & \\
\hline
\end{tabular}

* Excluding Zomba district because the denominator for the area covered by LEPRA/Likwenu is not exactly known.

Table 4(a). Expected number of new patients 1984-1988 by highland districts (group A) and lowland districts (group B). (95\% confidence limits in brackets.)

\begin{tabular}{|c|c|c|c|c|c|}
\hline & 1984 & 1985 & 1986 & 1987 & 1988 \\
\hline $\begin{array}{l}\text { Group A } \\
\text { Detection rate per } 1000\end{array}$ & $\begin{array}{c}0 \cdot 066 \\
(\cdot 040-0 \cdot 108)\end{array}$ & $\begin{array}{c}0 \cdot 056 \\
(\cdot 030-0 \cdot 106)\end{array}$ & $\begin{array}{c}0 \cdot 048 \\
(\cdot 022-0 \cdot 104)\end{array}$ & $\begin{array}{c}0 \cdot 041 \\
(\cdot 016-0 \cdot 102)\end{array}$ & $\begin{array}{c}0.035 \\
(\cdot 012-0 \cdot 101)\end{array}$ \\
\hline $\begin{array}{l}\text { Expected population } \\
\qquad(\times 1000)^{*}\end{array}$ & $1483 \cdot 1$ & $1533 \cdot 4$ & $1582 \cdot 7$ & $1632 \cdot 0$ & $1689 \cdot 2$ \\
\hline $\begin{array}{l}\text { Expected number of } \\
\text { new patients }\end{array}$ & $\begin{array}{c}98 \\
(60-160)\end{array}$ & $\begin{array}{c}86 \\
(46-162)\end{array}$ & $\begin{array}{c}76 \\
(35-165)\end{array}$ & $\begin{array}{c}67 \\
(27-167)\end{array}$ & $\begin{array}{c}59 \\
(20-170)\end{array}$ \\
\hline \multicolumn{6}{|l|}{ Group B } \\
\hline Detection rate per 1000 & $\begin{array}{c}0 \cdot 365 \\
(\cdot 292-0 \cdot 457)\end{array}$ & $\begin{array}{c}0 \cdot 329 \\
(\cdot 249-0 \cdot 434)\end{array}$ & $\begin{array}{c}0 \cdot 296 \\
(\cdot 213-0 \cdot 413)\end{array}$ & $\begin{array}{c}0 \cdot 267 \\
(\cdot 181-0 \cdot 393)\end{array}$ & $\begin{array}{c}0 \cdot 241 \\
(\cdot 155-0 \cdot 375)\end{array}$ \\
\hline $\begin{array}{l}\text { Expected population } \\
\qquad(\times 1000)^{*}\end{array}$ & $1193 \cdot 3$ & $1230 \cdot 4$ & $1267 \cdot 3$ & $1303 \cdot 9$ & $1346 \cdot 9$ \\
\hline $\begin{array}{l}\text { Expected number of } \\
\text { new patients }\end{array}$ & $\begin{array}{c}436 \\
(348-545)\end{array}$ & $\begin{array}{c}405 \\
(307-534)\end{array}$ & $\begin{array}{c}376 \\
(270-523)\end{array}$ & $\begin{array}{c}348 \\
(237-513)\end{array}$ & $\begin{array}{c}324 \\
(208-505)\end{array}$ \\
\hline
\end{tabular}

\footnotetext{
* Mid-year figure.
}

Table 4(b). Expected number of new patients 1984-1988 in the whole of Malawii.

\begin{tabular}{rrrrrr}
\hline 1984 & 1985 & 1986 & 1987 & 1988 \\
\cline { 2 - 5 } & 1334 & 1234 & 1237 & 1203 & 1181 \\
\hline
\end{tabular}


mid-year population estimates, taken from a recent publication of the National Statistical Office on Zomba, Malawi $i,{ }^{5}$ leads to the numbers of patients expected to be found annually in the years 1984-1988.

If we try to project the numbers of new leprosy patients to be detected annually from 1984 to 1988 for the whole of Malawi we have to add another 100 patients per year expected in Karonga District, where the incidence rate is probably about 1 per thousand and does not seem to be declining at present. ${ }^{4}$ For Lilongwe and Dedza Districts we feel justified in applying the detection rates projected for the A group (highland) districts, since the detection rates for 1983 in Lilongwe and Dedza Districts were 0.06 and 0.08 per thousand, respectively. This gives an expected number of new leprosy patients in Lilongwe and Dedza Districts (together) of 84 in 1984, 74 in 1985, 66 in 1986, 57 in 1987 and 50 in 1988. For Ntcheu District, which had a detection rate of 0.17 per thousand in 1983, we performed the same regression analysis as for groups $\mathrm{A}$ and $\mathrm{B}$ districts. This gives an expected number of new leprosy patients in Ntcheu District of 46 in 1984, 42 in 1985, 38 in 1986, 34 in 1987 and 31 in 1988.

Projections for the Pilot Project Area $^{2}$ and the Lower Shire Valley are considerably more hazardous due to the lack of entirely comparable data and are not presented in detail. The expected number of new leprosy patients in the Pilot Project Area is 294 in 1984, 303 in 1985, 311 in 1986, 320 in 1987 and 330 in 1988. For the Lower Shire Valley we estimate the expected number of new leprosy patients to be 256 in 1984, 264 in 1985, 271 in 1986, 279 in 1987 and 288 in 1988.

The total number of new leprosy patients which we would expect to be detected in the whole of Malawi, on the basis of the above assumptions, is shown in Table 4(b).

\section{Discussion}

When discussing the data presented in this paper and, in general, data which have been routinely collected, it would seem prudent to discuss first of all whether there is any indication that the data may be distorted by operational circumstances.

It would seem that one of our main findings is the decline in detection rates in the lowland districts (group B) at least since 1978 and in the highland districts (group A) at least since 1979. Two factors could cause this decline in detection rates NOT to reflect a decline in incidence rates of clinical leprosy in the communities.

One factor could be that LEPRA's mobile service and presence in these districts has declined since 1978-79 and the other factor could be that, as time went on, people in general lost interest in self-reporting with signs of clinical leprosy. There is, to our knowledge, no evidence for either.

Thus we think we can assume that the incidence rates of clinical leprosy have also declined, at least since 1978-79, parallel to the decline in the detection rates, 
as it would appear that the main backlog of leprosy patients prior to the presence of LEPRA's mobile service in these areas had come forward for examination and registration by 1977-78 (Table 3 and Figure 5).

A decline in incidence rates could in turn explain the trends observed both in a shift towards higher lepromatous rates in recent years and in shifts in the relative age distribution of new patients towards higher age groups. The first could be due to the longer incubation period of lepromatous leprosy, ${ }^{6}$ and the second could be due to breakdowns in immunity in older individuals infected some time in the past, events independent of current transmission of Mycobacterium leprae. On the other hand, if school surveys were carried out more frequently in the earlier years than in the later years of the period 1973-1983, it is possible that this might have exaggerated the apparent shift to higher age groups.

It has been suggested that increases in the lepromatous rate and shifts in the relative age distribution of new leprosy patients towards higher age groups are indicators of a decline in incidence rates of leprosy. ${ }^{7}$ However the rise in lepromatous rates could also, at least partly, be due to a selective drop in selfreporting among paucibacilliferous patients in highland and lowland areas.

Several factors might be at the root of the decline in incidence rates of clinical leprosy:

(i) BCG: BCG has been widely used in Malawi since 1972, when it was first introduced in mass campaigns aimed at individuals under 15 years of age. After the initial mass campaigns, BCG vaccination was left to the Under Five Clinics. As a result, a high proportion (over $50 \%)^{4}$ of Malawians born since 1958 have a BCG scar. Though the extent of protection imparted by BCG against leprosy in Malawi is still being analysed, it must be recognized that BCG has shown some degree of protection in every circumstance where this has been assessed ${ }^{8-10}$ Thus the decline in incidence rates and the trends towards older age groups revealed in Figures 2-4 could reflect, in part, the ageing cohort of BCG protected individuals.

(ii) Secular trends: Improving living conditions since Malawi's independence (1964) under the leadership of His Excellency the Life President Ngwazi Dr H Kamuzu Banda, may have contributed to the decline in incidence rates.

(iii) Effects of leprosy control activities: In theory, the introduction of chemotherapy against leprosy on a wide scale in Malawi, by the British Leprosy Relief Association (LEPRA) may have exerted some influence on trends of transmission of $M$. leprae, and thus have influenced the trends seen in our data. On the other hand, there is no strong evidence either here or in the literature ${ }^{11}$ which would lead us to attribute these trends to chemotherapy-based control.

Another main finding presented in this paper is the difference in endemicity between highland and lowland areas. Again, although this finding inevitably also reflects the method and intensity of case-finding activities in addition to the true incidence rate of leprosy in the community, we believe that the fivefold difference in detection rates between highland and lowland areas reflects a real difference 
and is not merely an artefact of case detection methods. The difference is unlikely to be spurious for the following reasons:

(i) If the boundary between high altitude and low altitude areas, which runs north to south, coincided with individual project boundaries, it would be difficult to know whether or not the observed difference in endemicity was real or owing to differences between the projects. However, the difference between highland and lowland areas is also observed within individual projects whose boundaries run from east to west.

(ii) Leprosy Control Assistants (LCAs) are transferred from one district to another within each project frequently enough to make it unlikely that the difference in endemicity observed is owing to individual activity and capacity of the staff (the less proficient LCAs are not as a matter of policy sequestered on the plateau).

(iii) The Field Officer/Medical Officer of a project is in frequent contact with his Assistant Field Officers and LCAs and we are confident that this has prevented the formation of different diagnostic practices within one project.

We therefore conclude that the difference in endemicity is real and not an artefact. The difference could be a function of a number of climatic, ecological, social and physiological differences between populations living in highland and lowland areas. In particular the relative distribution of species of 'environmental' mycobacteria in the soil might be different in the highland areas on the western plateau from the one in the lowland areas along the shore of Lake Malawi. It has been suggested that contact with certain environmental mycobacteria might enhance or decrease the immune response to an infection with M. leprae. ${ }^{12}$

Alternatively the higher humidity in the lowland areas ${ }^{13}$ might favour the survival of $M$. leprae outside the human bod $\mathrm{y}^{14}$ and thus facilitate transmission of $M$. leprae along the shore of Lake Malawi rather than on the Western Plateau.

On the other hand, ultraviolet light, which might reduce the immune response to $M$. leprae ${ }^{15}$ should be received in greater amounts on the skin in highland districts than along the shore of Lake Malawii.

A further obvious difference between A and B group districts is the population density in those parts of the districts where the land is cultivated and where people live. In B group districts the thus defined population density ranges from 129 in Salima district to 251 in Nkhotakota district, inhabitants per square kilometre, with an average of 197 per sq $\mathrm{km}$. In the A group districts the average is 113 per sq $\mathrm{km}$, with a range of 81 in Mzimba district to 183 in Dowa district, of inhabitants per square kilometre of cultivated land. The figures given are for $1966^{13}$ (recalculated from Table 4, page 210), later figures were not available to us, but we do not expect a substantial relative change in these population densities.

The third main finding seems to be the difference in sex ratios of new leprosy patients between the highland and lowland districts. The higher proportion of male patients in highland areas might be due in part to the relative excess of males 
in the highlands and in part to poorer access in highland areas. But we doubt that this could wholly explain the observed difference. Furthermore, given the well documented observation of a male excess among leprosy patients in most countries, it is the relative excess of female patients in the lowland areas of Malawi which is the most striking. This difference is borne out by the total population survey results of the LEP. ${ }^{4}$

Our projections for the next five years (1984-1988) have naturally wide confidence limits as indicated in Table 4(a). According to Figure 5, the annual decline is in the order of $12 \%$. This might be an exaggeration of the true rates of decline for two reasons. First, it is recognized that the backlog of new patients had not all self-reported by $1977-78$. However the proportion of backlog cases should have further decreased over the period. The effect of this should have magnified the apparent fall in incidence over the period. Second, it is recognized that more school surveys were carried out in the early years than the later years of the LCP in most districts. Thus the active case detection may have been more intense during the early years, again with the effect of exaggerating the fall in incidence over the period. In opposition to these trends, there may have been an increased tendency to self-report in recent years as the LCP activities became better established and more widely known. Taken together we suspect that the rates of decline as shown in Figure 5 may be an exaggeration of the true trend, but that nevertheless the incidence of leprosy is indeed falling throughout much of the country. And if so, the numbers of patients actually detected during 1984-1988 should, at least in the $\mathrm{A}$ and $\mathrm{B}$ group districts, not greatly exceed the numbers expected. If on the other hand, the numbers of patients actually detected fall far short of the numbers expected, one should not hesitate to look closely into operational changes introduced in the LEPRA Control Project after 1983.

\section{Conclusion}

Data presented in this paper indicate that there are at least two distinctly different leprosy endemic situations in Malawi (Central Africa). In the districts on the Central African Plateau (highland districts, or Western Plateau districts, altitude 900-1400 $\mathrm{m}$ above sea level) the level of endemicity is low and detection rates had fallen to 0.08 per thousand by 1983. In the districts in the Rift Valley (lowland districts or lakeshore districts, altitude $472-900 \mathrm{~m}$ above sea level) the level of endemicity is still five times higher than in the highland districts and the detection rates had only declined to 0.38 per thousand by 1983 .

The decline in detection rates in both areas has been observed since at least 1978-1979 and there is no evidence that this decline, which is similar in both areas, has been due to operational changes within the LEPRA Control Project. 


\section{Acknowledgments}

We thank all the staff, in particular the Leprosy Control Assistants, of the LEPRA Control Project for their dedicated efforts, over many years, in examining and treating the patients. Data were extracted and tabulated by Heleen Boerrigter, Kees Veltman, Tom Wolfs and Maud Zonjee, who went through all the individual patients' records. This help is most gratefully acknowledged.

We are indebted to the National Statistical Office for providing projectional population data per year per district.

For critical comments and suggestions on the first draft we thank Drs R J W Rees, R Feachem and in particular Dr P E M Fine. Jacqueline Clarkson gave us valuable statistical advice.

We also thank the Ministry of Health of the Republic of Malawi and the British Leprosy Relief Association (LEPRA) for permission to publish this paper.

\section{References}

1 Fine P. Problems in the Collection and Analysis of Data in Leprosy Studies. Lepr Rev, 1981; 52 (Suppl 1): 197-206.

2 Boerrigter G, Ponnighaus JM. 10 years' leprosy control work in Malâwi (Central Africa)—I. Methods and outcome after treatment. Lepr Rev, 1986; 57: 199-220.

${ }^{3}$ Malawi Population Census 1977. Final Report Volume I National Statistical Office, PO Box 333, Zomba. Printed by the Government Printer, Zomba, 1980.

${ }^{4}$ Ponnighaus JM, Fine PEM. Unpublished data.

5 Malaŵi Population Projections 1980-2000. National Statistical Office PO Box 333, Zomba, April 1984.

${ }^{6}$ Brubaker M, Binford $\mathrm{CH}$, Trautman JR. Occurrence of leprosy in US veterans after service in endemic areas abroad. Public Health Reports, 1969; 84: 1051-1058.

7 Irgens LM. Leprosy in Norway. Lepr Rev, 1980; 51 (Suppl 1): 1-130.

${ }^{8}$ Bechelli LM, Lwin K, Callego Garbajosa PG, Gyi MM, Uemura K, Sundaresan T, Tamondong C, Mateijka M, Sansarricq H, Walker J. BCG vaccination of children against leprosy: nine year findings of the controlled WHO trial in Burma. Bulletin of the World Health Organisation, 1974; 51: 93-99.

9 Scott GC, Russell DA, Boughton CR, Vincin DR. Untreated Leprosy. Probability for shifts in Ridley-Jopling classification. Development of 'flares', or disappearance of clinically apparent disease. Int J Lepr, 1976; 44: 110-122.

${ }^{10}$ Stanley SJ, Howland C, Stone MM, Sutherland I. BCG vaccination against leprosy in Uganda: final results. $J$ Hyg (Camb), 1981; 87: 233-48.

"Meade TW. How effective is the treatment of leprosy? Lepr Rev, 1977; 48: 3-8.

12 Rook GAW, Bahr GM, Stanford JL. The effect of two distinct forms of cell mediated response to mycobacteria on the protective efficacy of BCG. Tubercle, 1981; 62: 63-8.

${ }^{13}$ Lienau C. Malaŵi-Wissenschaftliche Buchgesellschaft. Wissenschaftliche Landerkunden, 1981; Band 20.

${ }^{14}$ Desikan KV. Viability of Mycobacterium leprae outside the human body. Lepr Rev, 1977; 48: 231-235.

15 Shepard CC. Animal Vaccination Studies with Mycobacterium leprae. Int J Lepr, 1983; 51, 519523. 